This paper isthe result of deliberations of the Society's discussion group on,

SEISMIC DESIGN OF DUCTILE MOMENT RESISTING REINFORCED CONCRETE FRAMES

SECTION J

\title{
DESIGN OF BEAM-COLUMN JOINTS
}

\author{
R. W. G. Blakeley*
}

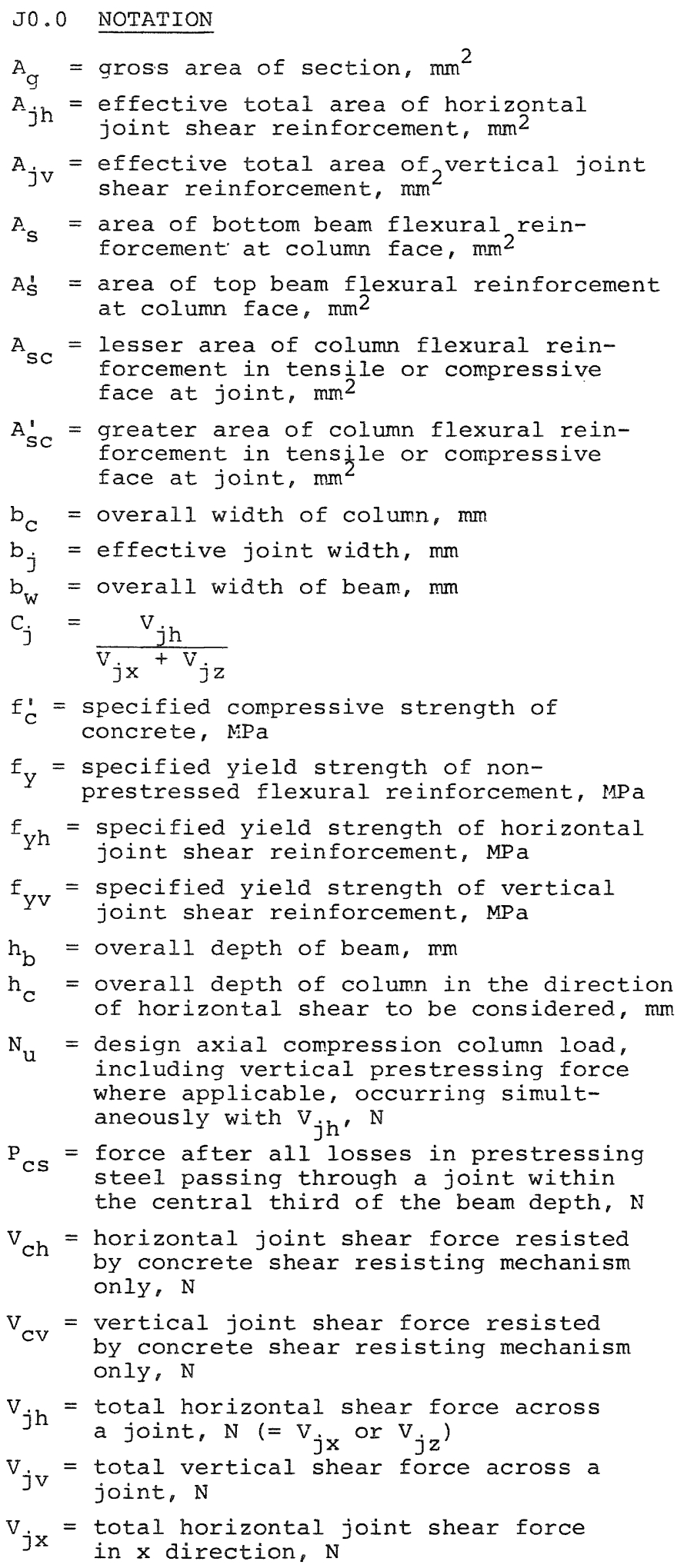

J0.0 NOTATION

$A_{g}=$ gross area of section, $\mathrm{mm}^{2}$

$A_{j h}=$ effective total area of horizontal joint shear reinforcement, $\mathrm{mm}^{2}$

$A_{j v}=$ effective total area of ${ }_{2}$ vertical joint shear reinforcement, $\mathrm{mm}^{2}$

${ }^{A_{S}}$ = area of bottom beam flexural reinforcement at column face, $\mathrm{mm}^{2}$

$A_{S}^{\prime}=$ area of top beam flexural reinforcement at column face, $\mathrm{mm}^{2}$

$A_{S C}=$ lesser area of column flexural reinforcement in tensile or compressive face at joint, $\mathrm{mm}^{2}$

$A_{S C}^{\prime}=$ greater area of column flexural reinforcement in tensile or compressive face at joint, $\mathrm{mm}^{2}$

$b_{c}=$ overall width of column, mm

$b_{j}=$ effective joint width, $\mathrm{mm}$

$\mathrm{b}_{\mathrm{w}}=$ overall width of beam, mm

$c_{j}=\frac{v_{j h}}{v_{j x}+v_{j z}}$

$f_{C}^{\prime}=$ specified compressive strength of concrete, $\mathrm{MPa}$

$f_{y}=$ specified yield strength of nonprestressed flexural reinforcement, MPa

$f_{y h}=$ specified yield strength of horizontal joint shear reinforcement, $\mathrm{MPa}$

$\mathrm{f}_{\mathrm{yv}}=$ specified yield strength of vertical joint shear reinforcement, $\mathrm{MPa}$

$h_{\mathrm{b}}=$ overall depth of beam, mm

$h_{c}=$ overall depth of column in the direction of horizontal shear to be considered, mm

$\mathrm{N}_{\mathrm{u}}$ = design axial compression column load, including vertical prestressing force where applicable, occurring simultaneously with $\mathrm{V}_{j h^{\prime}} \mathrm{N}$

$\mathrm{P}_{\mathrm{CS}}=$ force after all losses in prestressing steel passing through a joint within the central third of the beam depth, N

$\mathrm{V}_{\mathrm{ch}}=$ horizontal joint shear force resisted by concrete shear resisting mechanism only, $\mathrm{N}$

$\mathrm{V}_{\mathrm{CV}}=$ vertical joint shear force resisted by concrete shear resisting mechanism only, $\mathrm{N}$

$V_{j h}=$ total horizontal shear force across a joint, $\mathrm{N}\left(=\mathrm{V}_{j \mathrm{x}}\right.$ or $\left.\mathrm{V}_{j z}\right)$

$v_{j v}=$ total vertical shear force across a joint, $\mathrm{N}$

$v_{j x}=$ total horizontal joint shear force in $\mathrm{x}$ direction, $\mathrm{N}$

* Design Engineer, Ministry of Works and Development, Wellington.
$V_{j z}=$ total horizontal joint shear force in $\mathrm{z}$ direction, $\mathrm{N}$

$V_{\text {sh }}=$ horizontal design joint shear force to be resisted by horizontal joint shear reinforcement, $\mathrm{N}$

$\mathrm{V}_{\mathrm{SV}}=$ vertical design joint shear force to be resisted by vertical joint shear reinforcement, $N$

$v_{j h}=$ nominal horizontal shear stress in effective joint area, MPa

$\phi=$ capacity reduction factor $=0.85$

\section{J1.0 SCOPE}

Provisions are made for the design of beam-column joints subjected to the forces imposed when a frame sustains inelastic lateral displacements under earthquake loading. Both one-way and twoway frames are considered. Design for horizontal and vertical shear forces is required for both possible cases of plastic hinges forming in the beam or the column. Special concessions are made for significant column axial loads, for inclusion of prestressing steel, and for where members are designed so that plastic hinges will not form next to the joint. The objective of the design requirements is to make the joint stronger than the coincident hinging members, and therefore to avoid significant inelastic behaviour within the joint core.

\section{J2.0 DESIGN FORCES}

J2.1 The design shear forces acting on a beam-column joint should be evaluated from the maximum forces in all members coincident at the joint at flexural over-strength of the hinging member or members. At columns of two-way frames, where beams frame into the joint from two directions, these forces need only be considered in each direction independently.

J2.2 The magnitudes of the design horizontal shear force, $V_{j h}$, and the design vertical shear force, $V$ jvo in the joint should be evaluated from a rational analysis taking into account the effects of all forces acting on the joint.

\section{J3.0 GENERAL REQUIREMENTS}

J3.1 For shear design of the joint the capacity reduction factor, $\phi$, should be 0.85 .

J3.2 The nominal horizontal shear stress in the joint in either principal direction, $v_{j h}$, should not exceed $1.5 \sqrt{f_{C}^{\prime}}$

where $v_{j h}=\frac{v_{j h}}{\phi b_{j} h_{c}}$

J3.3 The effective joint width, $b_{j}$, should 
be taken as:

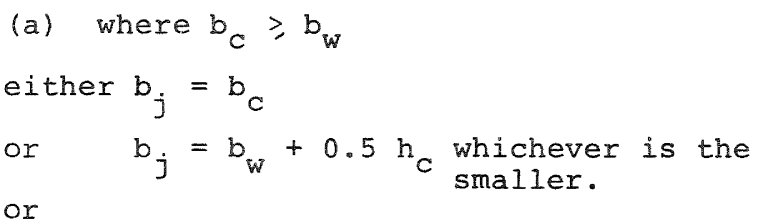

(b) where $b_{c}<b_{W}$

either $b_{j}=b_{w}$

or $b_{j}=b_{c}+0.5 h_{c} \begin{aligned} & \text { whichever is the } \\ & \text { smaller. }\end{aligned}$

\section{J4.0 REINFORCEMENT}

\section{J4.1 General}

J4.I.I A rational system should be provided to resist the horizontal and vertical shear forces induced in the joint.

$\mathrm{J} 4.1 .2$ The provisions of $\mathrm{J} 4.2$ and $\mathrm{J} 4.3$ apply to joints in which the shear reinforcement comprises horizontal and vertical stirrups or bars. The required horizontal and vertical joint shear reinforcement should be placed within the effective joint width, defined in J3.3, relevant to each direction of loading.

J4.1.3 special joint reinforcement details, such as diagonal bars bent across the joint in one or both directions, or other special devices, may be used if it is shown by analysis and/or tests that the shear forces that may be induced during large inelastic deformations of the coincident beams are adequately transferred by an acceptable mechanism and that anchorage of the flexural reinforcement across the joint is assured.

\section{J4.2 Horizontal Joint Shear}

J4.2.1 The horizontal design shear force to be resisted by the horizontal joint shear reinforcement should be

$\mathrm{v}_{\mathrm{sh}}=\frac{\mathrm{v}_{\mathrm{jh}}}{\phi}-\mathrm{v}_{\mathrm{ch}}$

where $V_{c h}$ is the allowable horizontal shear carried by the concrete shear resisting mechanism.

J4.2.2 The value of $V_{\text {ch }}$ should be assumed to be zero except in the following cases:

(a) When the minimum average compressive stress on the gross area of the column above the joint, including prestress where applicable, exceeds $0.1 \mathrm{f}_{\mathrm{C}}^{\prime} / \mathrm{C}_{j}$

$v_{c h}=0.25\left(I+\frac{f_{c}^{\prime}}{25}\right) \sqrt{\frac{C_{j}^{N} u}{A_{g}}-\frac{f_{c}^{\prime}}{10}}\left(b_{j} h_{c}\right)$

(b) When beams are prestressed through the joint

$\mathrm{V}_{\mathrm{ch}}=0.7 \mathrm{P}_{\mathrm{CS}}$

where $\mathrm{P}_{C S}$ is the force after all losses in the prestressing steel that is located within the central third of the beam depth.

The values of $\mathrm{V}_{\mathrm{Ch}}$ obtained from Eq. (J-3) and Eq. ( $\mathrm{J}-4)$ may be added when applicable. (c) When frame design precludes the formation of any beam plastic hinges at the joint, or when all beams at the joint are detailed so that the critical section of the plastic hinge is located at a distance of not less than the depth of the member or $500 \mathrm{~mm}$, whichever is greater. away from the column face, or for external joints where flexural steel is anchored outside the column core in a stub in accordance with E4.4.4

$v_{c h}=\frac{A_{s}}{A_{s}^{!}} \frac{V_{j h}}{2}\left(1+\frac{C_{j} N_{u}}{0.6 A_{g} f_{C}^{!}}\right)$

except that, where the axial column load results in tensile stresses over the gross concrete area, the value of $\mathrm{V}_{\mathrm{Ch}}$ should be linearly interpolated between the value given by Eq. $(\mathrm{J}-5)$ with $\mathrm{N}_{\mathrm{U}}$ taken as zero, and zero at an axial tensile stress of $0.2 f_{C}^{\prime}$. Thereafter the entire horizontal joint shear should be resisted by reinforcement.

J4.2.3 The horizontal shear reinforcement should be capable of carrying the design shear force to be carried by the reinforcement, $V_{\text {sh }}$ across a corner-to-corner diagonal tension crack plane. The effective total area of horizontal reinforcement that crosses the critical failure plane,

determined according to the orientation of the individual tie legs with respect to this failure plane, and that is within the effective joint width, $b_{j}$, should not be less than

$A_{j h}=\frac{V_{s h}}{E_{y h}}$

Any tie leg between bends around column bars that does not cross the potential failure plane, or is shorter than onethird of the dimension of the column in the appropriate plane of bending, should be neglected.

The required number of horizontal sets of stirrup ties or bars should be placed between the outermost layers of the top and bottom beam reinforcement, and should be distributed as uniformly as is practicable.

\section{J4.3 Vertical Joint shear}

J4.3.1 The vertical design shear force to be resisted by the vertical joint shear reinforcement should be

$\mathrm{v}_{\mathrm{sV}}=\frac{\mathrm{v}_{j \mathrm{v}}}{\phi}-\mathrm{v}_{\mathrm{cv}}$

where $\mathrm{V}_{\mathrm{CV}}$ is the allowable vertical shear carried by the concrete shear resisting mechanism.

J4.3.2 The value of $V_{C V}$ should be determined from

$v_{C V}=\frac{A_{S C}}{A_{S C}^{!}} \frac{V_{j v}}{2}\left(1+\frac{C_{j} N_{u}}{0.6 A_{g}^{f}}\right)_{C}^{\prime}$

except

(a) Where the axial column load results in tensile stresses over the gross concrete area, the value of $\mathrm{V}_{\mathrm{CV}}$ should be linearly 
interpolated between the value given by Eq. $(\mathrm{J}-8)$ with $\mathrm{N}_{\mathrm{u}}$ taken as zero, and zero at an axial tensile stress of 0.2 f́. Thereafter the entire vertical joint shear should be resisted by reinforcement.

and

(b) Where plastic hinges are expected to form in the column above or below the joint, as part of the primary seismic energy dissipating mechanism, $V_{\text {fy }}$ should be assumed to be zero for any axial load.

J4.3.3 The vertical joint shear reinforcement should consist of intermediate column bars, placed in the plane of bending between corner bars, or vertical stirrup ties, or special vertical bars placed in the column and adequately anchored to transmit the required tensile forces within the joint.

J4.3.4 The area of vertical joint shear reinforcement within the effective joint width, $b_{j}$, should not be less than

$A_{j v}=\frac{V_{s v}}{f_{Y v}}$

J4.3.5 The spacing of column bars in each plane of any beams framing into a joint should not exceed $200 \mathrm{~mm}$, and in no case should there be less than one intermediate bar in each side of the column in that plane.

\section{J4. 4 Confinement}

The horizontal transverse confinement reinforcement in beam-column joints should not be less than that required by H6.1, except for joints connecting beams at all four column faces that are not expected to form plastic hinges or are designed according to J4.2.2 (b) or (c), in which case the transverse joint reinforcement may be reduced to one half of that required in $\mathrm{H} 6.1$, but in no case should the stirrup tie spacing in the joint core exceed ten times the diameter of the column bar or $150 \mathrm{~mm}$, whichever is less.

\section{J5.0 ECCENTRIC BEAM-COLUMN JOINTS}

J5.1 The eccentricity of any beam relative to the column into which it frames should not exceed that permitted in E4.1, except as allowed in J5.2(b).

J5.2 All joint design provisions of this section apply except that

(a) In addition to the effective joint width limits of J3.3, the following should apply:

$b_{j} \leqslant \frac{b_{w}}{2}+\frac{b_{c}}{2}+0.25 h_{c}-e$

(b) Where the eccentricity exceeds that permitted in E4.1, all of the required flexural steel in the column should be placed within the effective joint area, $b_{j} h_{C}$. Additional longitudinal column reinforcement should be placed outside of the effective joint area in accordance with H5.2.

\section{COMMENTARY}

\section{CJ0.0 NOTATION}

$A_{\ell}=$ area of leg of tie set
$C^{\prime}=$ compression force in the concrete in the flexural compression zone of a beam

c' = compression force in the compression reinforcement of a beam

$f_{Y}^{*} \quad=$ overstrength of longitudinal reinforcement, generally $1.25 \mathrm{f}_{\mathrm{y}}$ for Grade 275 steel

$I_{1}, I_{2}=$ span of beam between centre-to-centre of supports

$1_{1 n}, 1_{2 n}=l_{\text {ength }}$ of clear span of beam,

In, ${ }^{2}$ measured face-to-face of supports

$1_{c}{ }^{1}{ }_{C}^{\prime}=$ height of column, centre-to-centre of floors or roof

$M_{1}^{*}, M_{2}^{*}=$ flexural over-capacity of beam section at faces of a column

$\mathrm{T}$ = tension force in tension reinforcement

$\mathrm{T}_{\mathrm{p}}, \mathrm{T}_{\mathrm{p}}^{\prime}=$ prestressing force at faces of $\mathrm{a}$ column at flexural capacity of section

$\mathrm{V}_{\text {col }}=$ horizontal shear force across a column

\section{CJ1.0 SCOPE}

Severe conditions of shear and of anchorage of flexural reinforcement can arise in joints. Inelastic behaviour in the form of yield of shear reinforcement or loss of bond to flexural reinforcement can lead to rapid loss of strength under seismic conditions and is, therefore, to be avoided.

\section{CJ2.0 DESIGN FORCES}

CJ2.1 In order to provide adequate reserve strength within a joint, the forces in the coincident beams and columns must be evaluated at flexural overstrength of the hinging members. Generally the hinging members will be the beams, except in one or two-storey frames or at the top of columns in multi-storey frames where columns may be designed to hinge. Where beam flexural reinforcement is detailed to force the plastic hinge to form away from the column face, the forces in the beam at the column face should be determined for flexural overstrength at the critical section of the plastic hinge. Allowance for overstrength of flexural reinforcement should be as recommended in E4.4.5. Provisions for the contribution of the slab reinforcement, where applicable, should be not less than those recommended in E4.4.2. Because that clause represents a lower bound of effective slab steel for flexural design purposes, a greater contribution from the slab should be assumed appropriate to the upper bound required for joint shear design.

The basis for design of beam-column joints in two-way frames, by consideration of forces acting in each principal direction independently, is recent (1977) testing at University of Canterbury. A joint designed on this basis and extensively tested, including several major cycles of concurrent hinging of beams in both principal directions, performed satisfactorily. While it may be undesirable to base design provisions on only one test, the complexity of such tests means that there is unlikely to be further test information available in the foreseeable future. 
When stiff structural systems, such as shear walls, prevent yielding in beams or columns in one or both principal directions of the building, a rational analysis should be used to determine the forces in the frame members at the maximum anticipated seismic loading.

CJ2.2 The internal forces imposed on the joint by flexure of members in one vertical plane only at the connection are shown in Fig. CJl, for both internal and external beam-column joints. The concentrated tension and compression forces in both beam and column, minus the much smaller values of column and beam shears, induce resultant shear stresses in the panel zone. The horizontal shear force $V_{j h}$ across a general internal joint is

$V_{j h}=T+C_{C}^{\prime}+C_{s}^{\prime}+T_{p}-T_{p}^{\prime}-V_{\operatorname{col}}$

For conventionally reinforced concrete members without prestressing, this simplifies to:

internal joints $V_{j h}=A_{S}^{\prime} f_{y}^{*}+A_{S} f_{y}^{*}-V_{c o l}$

external joints $V_{j h}=A_{s}^{\prime} f_{y}^{*}-V_{c o l}$

The value of the column shear, $V_{c o l}$, will depend on the column moment gradients above and below the joint. However, from Fig. CJ2 its value may be estimated using a mean moment gradient, thus

$\mathrm{V}_{\mathrm{CO}}=2\left({\frac{I_{1}}{I_{1 \mathrm{n}}}}^{\mathrm{M}_{1}^{*}}+\frac{I_{2}}{I_{2 \mathrm{n}}} \mathrm{M}_{2}^{*}\right) /\left(I_{\mathrm{c}}+I_{\mathrm{c}}^{\prime}\right)$

Alternatively, the maximum horizontal joint shear may be derived from the gradient of the column moment diagram through the joint.

When necessary the value of the vertical joint shear force, $V_{j v}$, may be derived from similar considerations to the above for horizontal joint shear force. Alternatively, the vertical joint shear force may be approximated as follows:

$v_{j v} \simeq v_{j h} \frac{h_{b}}{h_{c}}$

\section{CJ3.0 GENERAL REQUIREMENTS}

CJ3.2 An upper limit for joint shear stress is specified to safeguard the core concrete against excessive diagonal compressive stresses. The horizontal nominal stress corresponding to the critical horizontal shear force, $V_{j h}$, is based on the nominal gross horizontal area of the joint $b_{j} h_{C}$ as defined in $\mathrm{J} 3.3$.

CJ3.3 A limitation is placed on the area of a joint core which may be considered to be effective in resisting joint shear when the beam or beams framing into a connection are considerably narrower than the column. The effective joint width, $b_{j}$, where $b_{j}$ is less than $b_{C}$ is illustrated in Fig. CJ3. Where the beam is wider than the column, the effective joint width is assumed to spread beyond the bounds of the column in a similar manner.

\section{CJ4.0 REINFORCEMENT}

CJ4.1.1 The observed failure plane due to shear in joints of one-way frames bisects the joint along a diagonal from one beamcolumn edge to another $(1,2,3,4)$. Under cyclic loading, the diagonal tension cracks open and close in each direction as the direction of load alternates. If the joint reinforcement yields so that the cracks become wide, relative shear displacements along the crack can lead to uneven bearing followed by grinding of the concrete and general deterioration of the joint. Generally this will not occur if any yielding is limited to isolated tie legs.

Shear transfer across the panel zone may be idealised as due, in varying proportions, to four mechanisms: diagonal strut action, truss action, aggregate interlock and dowel action. Concrete compression forces tend to be transferred directly by diagonal strut action. Although, theoretically, diagonal strut action requires no shear reinforcement, the diagonal compression force creates a splitting force perpendicular to it and reinforcing steel is required to control the width of the cracks. Those forces induced in the panel zone through bond to the reinforcing bars tend to be transferred by a truss mechanism comprising a number of diagonal compression struts in the concrete, parallel to the potential failure plane, and tension ties in the horizontal and vertical steel, as shown in Fig. CJl. Usually horizontal stirrup ties are provided to resist the horizontal forces but the vertical strut components must be resisted by intermediate column bars, vertical stirrup ties or special vertical bars. Aggregate interlock may only be relied on where the cracks are narrow and the bearing surfaces not worn. Dowel action of the ties across the diagonal tension cracks will only be significant where the cracks are wide and the joint is likely to have already deteriorated.

CJ4.1.3 Innovative details which encourage a more direct transfer of forces across the panel zone, such as main beam or column steel bent diagonally across the joint or encouragement of arch action by use of mechanical anchors on flexural steel at the extremities of the joint (5), appear attractive. Any arrangement which represents a major departure from previously used details should be tested before adoption.

\section{CJ4.2 Horizontal Joint Shear}

CJ4.2.1 The horizontal joint shear force is assumed to be transferred between the levels of the top and bottom beam flexural reinforcement by strut action in the concrete core, $\mathrm{V}_{\mathrm{Ch}}$, and by a truss mechanism, $\mathrm{V}_{\mathrm{sh}}$. The dependable shear capacity, using $\phi=0.85$, is then equated to the overstrength shear demand, Vjh.

CJ4.2.2 When plastic hinges form under reversed load in reinforced concrete beams immediately adjacent to the joint core, wide cracks develop at the column face and moment tends to be transferred by a steel couple. The major part or all of the internal compression force in the beams is then transferred to the joint by the flexural reinforcement. Consequently it must be assumed for this condition, and 
when column axial loads are low, that all the beam forces are transmitted by a truss mechanism and $\mathrm{V}_{\mathrm{ch}}=0$. Recent recommendations (6) allowing the concrete to carry some shear are not considered justified in that case.

$V_{\text {ch }}$ is assumed to be effective in the following circumstances:

(a) With increasing axial loads on columns the internal column concrete compressive forces tend to increase, with consequent increase in the width of the diagonal compression strut. When axial compression exceeds $0.1 \mathrm{f}_{c}^{\prime}$, sufficient bond transfer from the flexural reinforcement is assumed to occur within the strut region, even considering yield penetration into the joint, to allow some of the beam bar forces to be transferred by this strut.

Eq. $(J-3)$ is similar to Eq. (F.I) for members subject to flexure and axial load. On the basis of analyses and limited test data $(7)$, this equation is considered to underestimate the advantages of column axial load on joint shear strength and will be reviewed when further evidence is available.

The factor $c_{j}$ is introduced to allocate the effect of axial compression to the two principal directions $\mathrm{x}$ and $\mathrm{z}$ of the earthquake loading when joint shears $V_{j x}$ and $V_{j z}$ are concurrently developed. The effect of this provision is to prevent the advantages of full axial load being utilised in each principal direction for the independent shear design provisions of J2.1. For a symmetrical two-way frame $\mathrm{C}_{j}=0.5$; for a one-way frame $C_{j}=1.0$.

(b) Prestressing within the central area of the beam has the effect of encouraging joint concrete strut action and of restraining diagonal tension cracking $(2,3)$. However, prestressing steel near the extreme fibres of the section sustains permanent sets and loss of prestress after inelastic beam hinge rotations. Thus, only the prestressing steel at the central third of the beam depth may be considered for shear resistance in the joint. It should be recognised that where prestressed concrete beams support cast insitu floor slabs, the effective prestress is likely to be distributed into the slab. The full provisions should not be applied unless the prestress can be relied on, for example where the floor system is not restrained to the beam. Where the floor slab is monolithic with the beam and the prestress is indeterminate, bonded cables will still serve a function of restraining diagonal tension joint cracks and half the allowance of Eq. (J-4) may be assumed.

Because the contributions to shear strength of the joint from column axial load and from beam prestress involve different mechanisms, the contributions toward $\mathrm{V}_{\mathrm{Ch}}$ may be added.

(c) The advantages for shear design where beams are detailed so that plastic hinges are forced to form away from the column face include the prevention of beam bar yield penetration with consequent loss of bond in the joint region, the increased contribution of the concrete strut to shear transfer, and the confinement effects of the beams where wide cracking at the column face is avoided. Case studies of the contribution of the concrete strut to shear transfer have been made based on a model shown in Fig. CJ4. The shear forces from the beams and columns may be assumed as being transferred in the corresponding compression zones only. $\mathrm{V}_{\mathrm{Ch}}$ and $\mathrm{V}_{\mathrm{CV}}$ are the horizontal and vertical components of the diagonal thrust $\mathrm{D}$ that will pass through the centre of the joint core. The case studies have shown that approximately one half of the horizontal joint shear, $V_{j h}$, can be transferred by the diagonal concrete strut when there is zero axial compression on the column and where there is equal top and bottom beam steel. The proportion of joint shear resisted by the diagonal strut increases with increasing axial load and decreases as the ratio of areas of top and bottom beam steel increases. These trends are represented in Eq. (J-5) and illustrated in Fig. CJ5. The intention of $\mathrm{Eq}$. (J-5) is that $A_{S}^{\prime}$ is equal to or greater than $A_{S}$, which normally will mean that $A_{S}$ is the area of top beam steel and $A_{S}$ the area of bottom beam steel. When columns are subjected to axial tension it is assumed that the shear resistance from diagonal strut action diminishes. When the axial tensile stress on the gross column section exceeds $0.2 f_{c}^{\prime}$ full joint shear reinforcement is required. In external beam-column joints Favourable diagonal strut action is developed provided anchorage of flexural bars is assured, particularly with use $9 \frac{f}{4}$ external stubs. Testing of such joints $(4)$ indicates that $\mathrm{Eq}$. ( J-5) represents satisfactorily the contribution of the concrete strut.

CJ4.2.3 Research on planar beam-column assemblies has shown that the corner-tocorner crack across the joint represents the critical failure plane. Strain gauge readings on ties in joint cores $(1,2,3,4)$ have shown considerable scatter of strains within any tie set and moderate variation of effectiveness of different tie sets. In particular, tie sets in the central region of the core tend to be more effective than those near the top and bottom of the core. It has been shown(3) that yield of isolated tie legs need not lead to joint disintegration, and it is felt that the normal capacity reduction factor of 0.85 allows sufficient account to be taken of the variation of effectiveness of different tie sets.

In the case of stirrup ties of diagonal shape in plan, the appropriate component of each tie leg crossing the failure plane in the direction of the joint shear force should be considered.

Stirrup ties should be placed adjacent to the top and bottom beam flexural reinforcement as in this position they are effective in bond transfer from the flexural bars. Uniform spacing of tie sets is consistent with the desired uniform diagonal crack spacing.

\section{Cu4.3 Vertical Joint Shear}

CJ4.3.1 Vertical joint shear reinforcement is required to complete a truss mechanism capable of resisting diagonal compressive forces. The design of such reinforcement 
may be made using the same approach as that for the horizontal joint shear reinforcemert. The vertical joint shear force may be approximated as suggested in $\mathrm{Eq} .(\mathrm{CJ}-4)$.

CJ4.3.2 Generally columns will not yield when the flexural overstrength of the beams. adjacent to the joint, is developed. ThereFore, the concentrated compression forces in the columns may be expected to be transferred by direct concrete strut action. These forces also provide partial vertical restraint to the joint truss mecharism. thereby reducing the vertical joint steel requirements. Case studies indicate that $\mathrm{V}_{\mathrm{CV}}$ increases sharply with increasing axial load.

Where $v_{c h}$ may be determined according to $\mathrm{Eq} .(\mathrm{J}-5)$ and $\mathrm{V}_{\mathrm{CV}}$ may be determined according to $\mathrm{Eq}$. $(\mathrm{J}-8)$, then in computing vertical steel

$v_{c v}=v_{c h} \frac{h_{b}}{h_{c}}$

Where frame design is on the basis of column plastic hinging, for example in the columns of one of two-storey frames or in the top storey of a multi-storey building, these provisions require that the vertical joint shear reinforcement be designed on the same basis as the horizontal joint shear reinforcement for hinging beams.

CJ4.3.3 The simplest solution to provision of vertical shear reinforcement is to use the existing column bars within the joint core. The intermediate bars are not expected to be fully stressed by column flexure alone. If extra bars are placed they need not extend over the full height of the column, but they need to be adequately anchored in the column above and below the joint.

CJ4.3.4 When only four corner bars are required for the column flexural reinforcement, at least one intermediate vertical bar must be placed in each face in each plane of bending. For larger columns two or more intermediate vertical column bars, situated between corner bars, should pass through the joint with spacing not exceeding $200 \mathrm{~mm}$. This requirement is to allow truss action consistent with uniformly spaced diagonal tension cracks.

\section{CJ4.4 Confinement}

The diagonal compression stresses induced within the joint core may be very large and hence effective confinement is necessary. When plastic hinges could form in the beams adjacent to the column faces, the minimum transverse reinforcement required in the joint is the same as the confinement reinforcement recommended for the column ends immediately above or below the joint. However, in two-way frames when the beam plastic hinges are forced to form away from the column faces, or where the column will hinge rather than the beams at a joint, the beam region adjacent to the column is assumed to provide adequate transverse confinement. Consequently the confining steel may be reduced to one half of that otherwise required. To safeguard column bars against bucking, particularly those at the corners of rectangular column sections which may be outside the joint core, the tie spacing is limited.

\section{CJ5.0 ECCENTRIC BEAM-COLUMN JOINTS}

When the axes of beams and columns are eccentric at a connection, secondary actions such as torsion will be generated. The behaviour of joints under the combined shear and torsion is more complex than those under shear alone and is as yet unresearched. Evidence from earthquakes shows that such joints are to be avoided. Torsion introduced through such details caused heavy damage in buildings during the Tokachioki earthquake.

CJ5.2 (a) The effect of this extra limit on effective joint width, $b_{j}$, is to follow the same assumption made for eocentric joints as shown in Fig. CJ3; but to cover the case of an eccentric joint where the face of the column is closer than $0.25 \mathrm{~h}_{\mathrm{c}}$ to the side of the beam for both possibilities of the beam being narrower or wider than the column

(b) In circumstances where eccentricities exceeding the limit of E4.I cannot be avoided, all of the required column flexural steel as well as all of the required joint shear steel is to be included within the effective joint area, $b_{j} h_{C}$. Outside of this area additional column longitudinal reinforcement and transverse reinforcement for confinement will be required.

\section{REFERENCES}

1. Park, R, and Paulay, T., "Behaviour of Reinforced Concrete External Beam. Column Joints under Cyclic Loading", Vol. I, Paper 88 , Proceedings 5 th World Conference on Earthquake Engineering, Rome, 1973, pp $772-781$

2. Park, R. and Thompson, K. J., "Proaress Report on Cyclic Load Tests on Prestressed, Partially Prestressed and Reinforced Concrete Interior Beam-Column Assemblies", Bulletin of the N.Z. National Society for Earthquake Engineering, Vol. 8, No. 1, March, 1975, pp 12-37.

3. Blakeley, R.W.G., Edmonds, F. D., Megget, L. M., and Priestley, M. J. N., "Performance of Large Reinforced Concrete BeamColumn Joint Units Under Cyclic Loading", Proceedings 6 th World Conference on Earthquake Engineering, New Delhi, January 1977, $6 \mathrm{pp}$.

4. Blakeley, R.W. G., Megget, I. M. and Priestley, M. J. N., "Seismic Performance of Two Full Size Reinforced Concrete Beam-Column Joint Units" Bulletin of the N.Z. National Society for Earthquake Engineering, Vol. 8, No. 1, March, 1975 pp 38-69.

5. Eenwick, R. C. and Irvine, H. M. "Reinforced Concrete Beam-Column Joints for Seismic Loading" "Bulletin of the N.Z. National Society for Earthquake Engineering, Vol. 10, No. 4, December 1977.

6. ACI-ASCE Committee 352, "Recommendations for Design of Beam-Column Joints in Monolithic Reinforced Concrete Structures", ACI Journal, Proceedings V 69, No. 7, July 1976, pp 375-393.

7. Hanson, N. W., "Seismic Resistance of Concrete Frames with Grade 60 Reinforcement, Journal of the structural Division, ASCE, Vol. 97, ST 6, June 1971, pp $1685-1700$.

Paper received 25 November, 1977. 


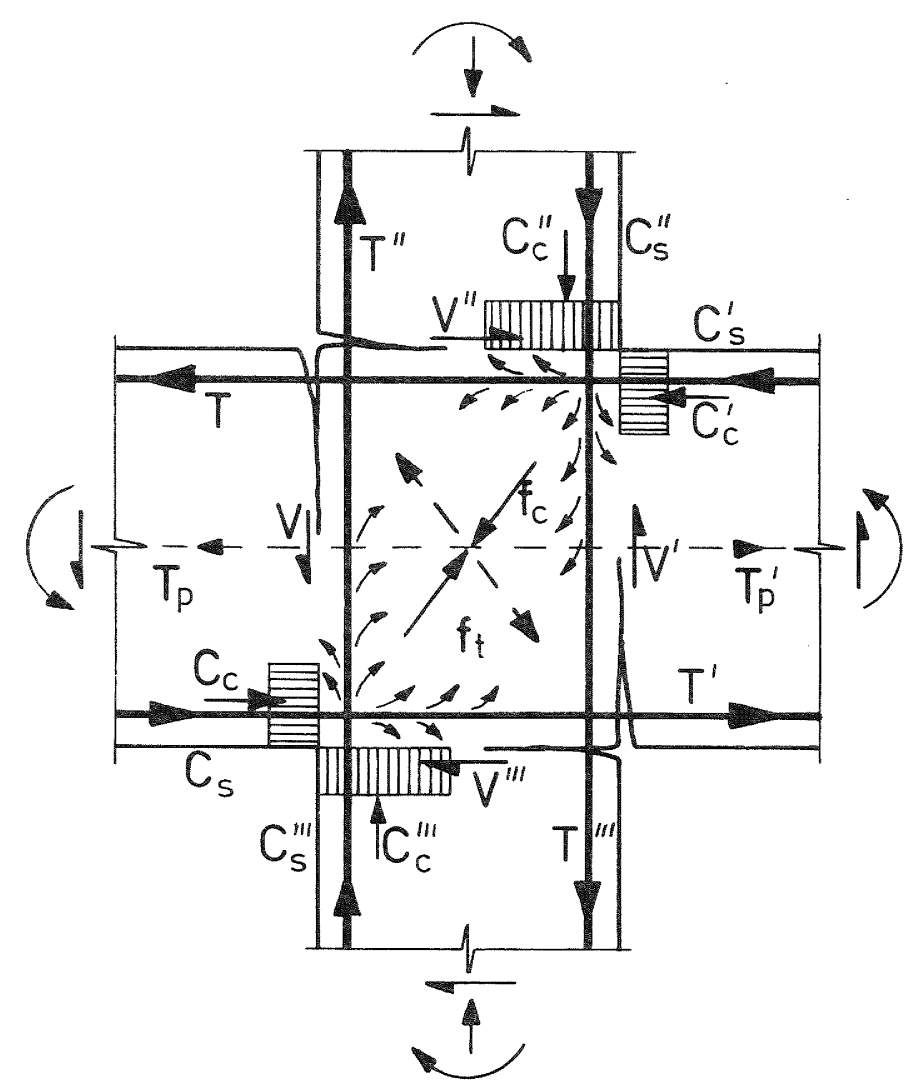

FORCES ON INTERNAL JOINT

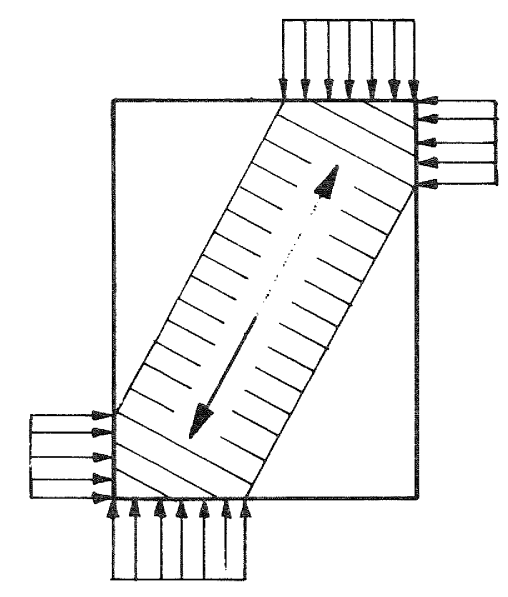

Transfer of concrete compression forces

STRUT ACTION

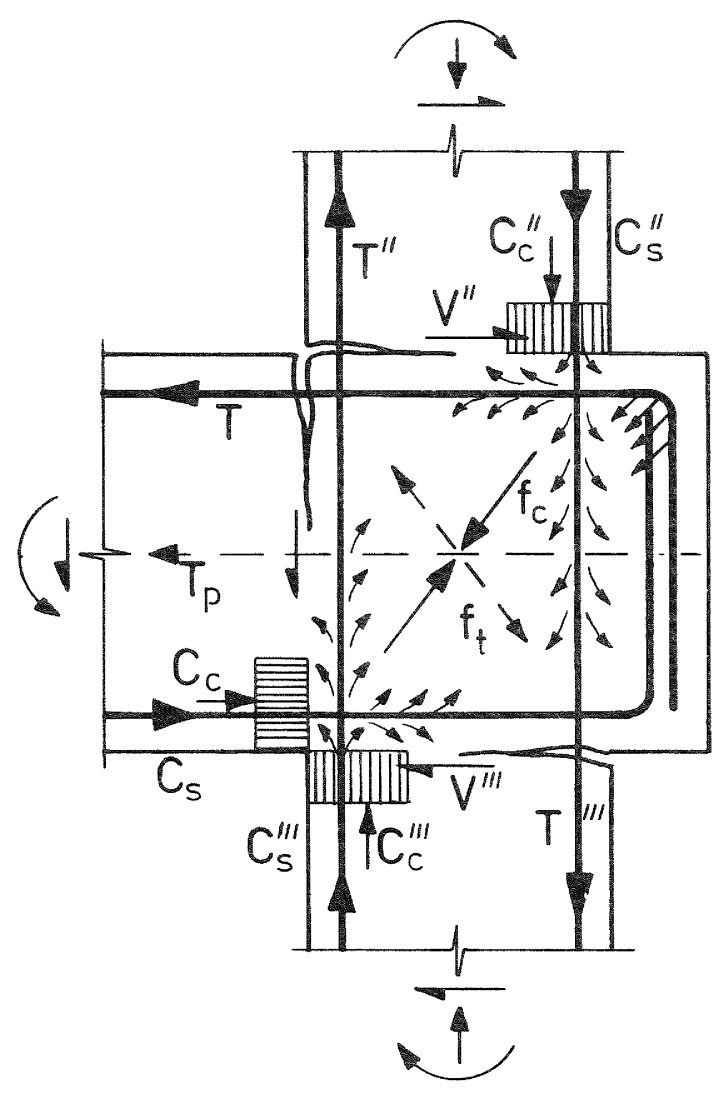

FORCES ON EXTERNAL JOINT

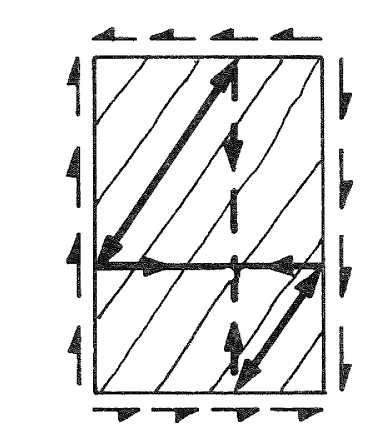

Transfer of steel bond forces

TRUSS ACTION 


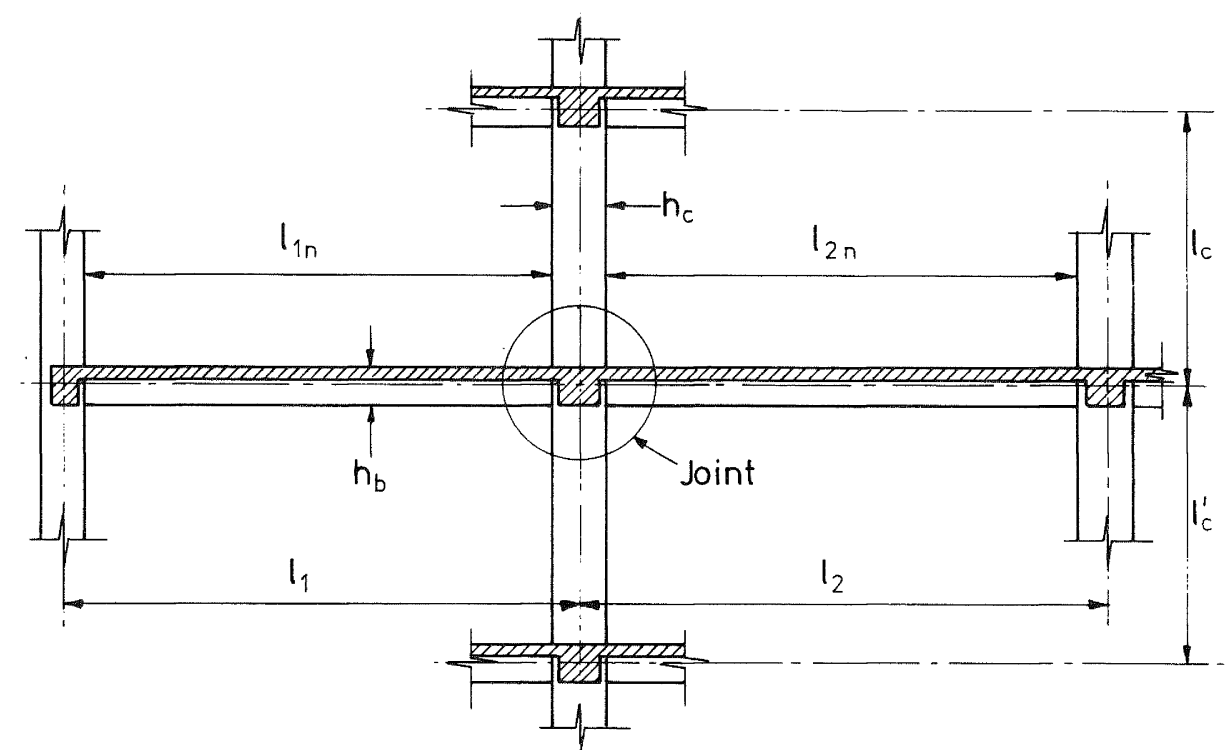

FIGURE CJ2: FRAME DIMENSIONS AT INTERNAL BEAM-COLUMN JOINT FIGURE
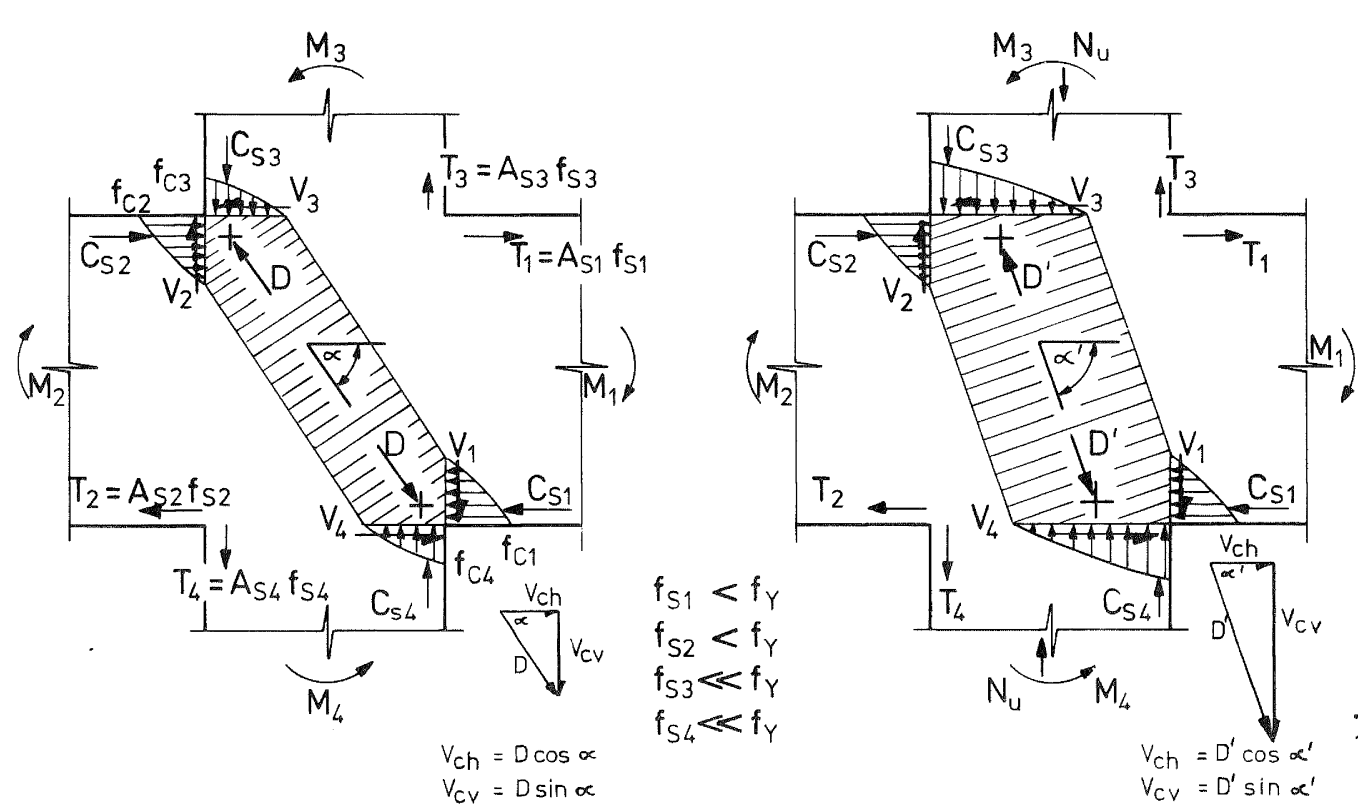

CJ4: MECHANISM OF SHEAR TRANSFER BY A DIAGONAL STRUT IN "ELASTIC" BEAM-COLUMN JOINTS

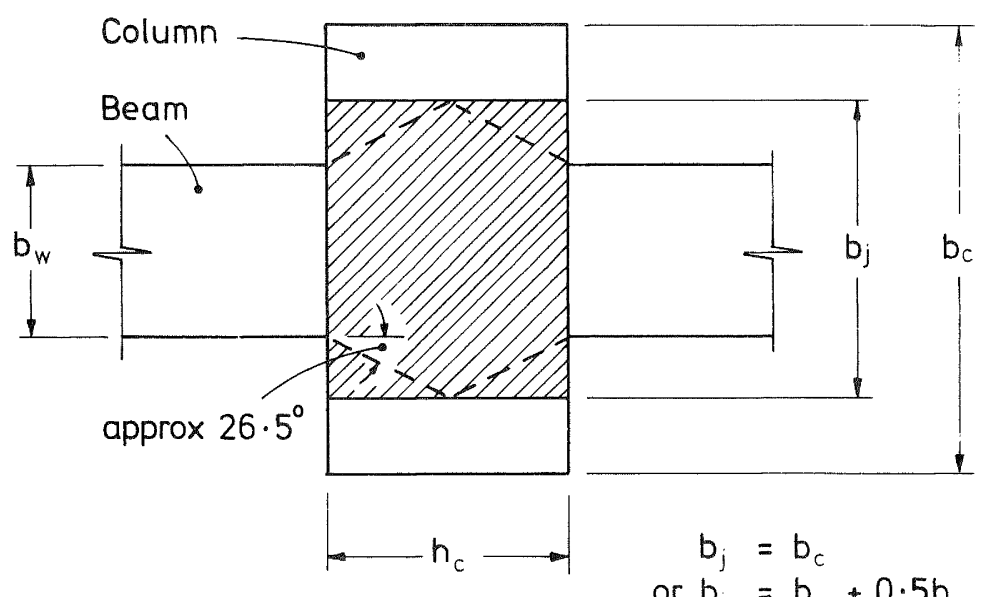

or $b_{j}=b_{w}+0.5 h_{c}$ whichever is smaller

CJ3: EFFECTIVE JOINT AREA FIGURE

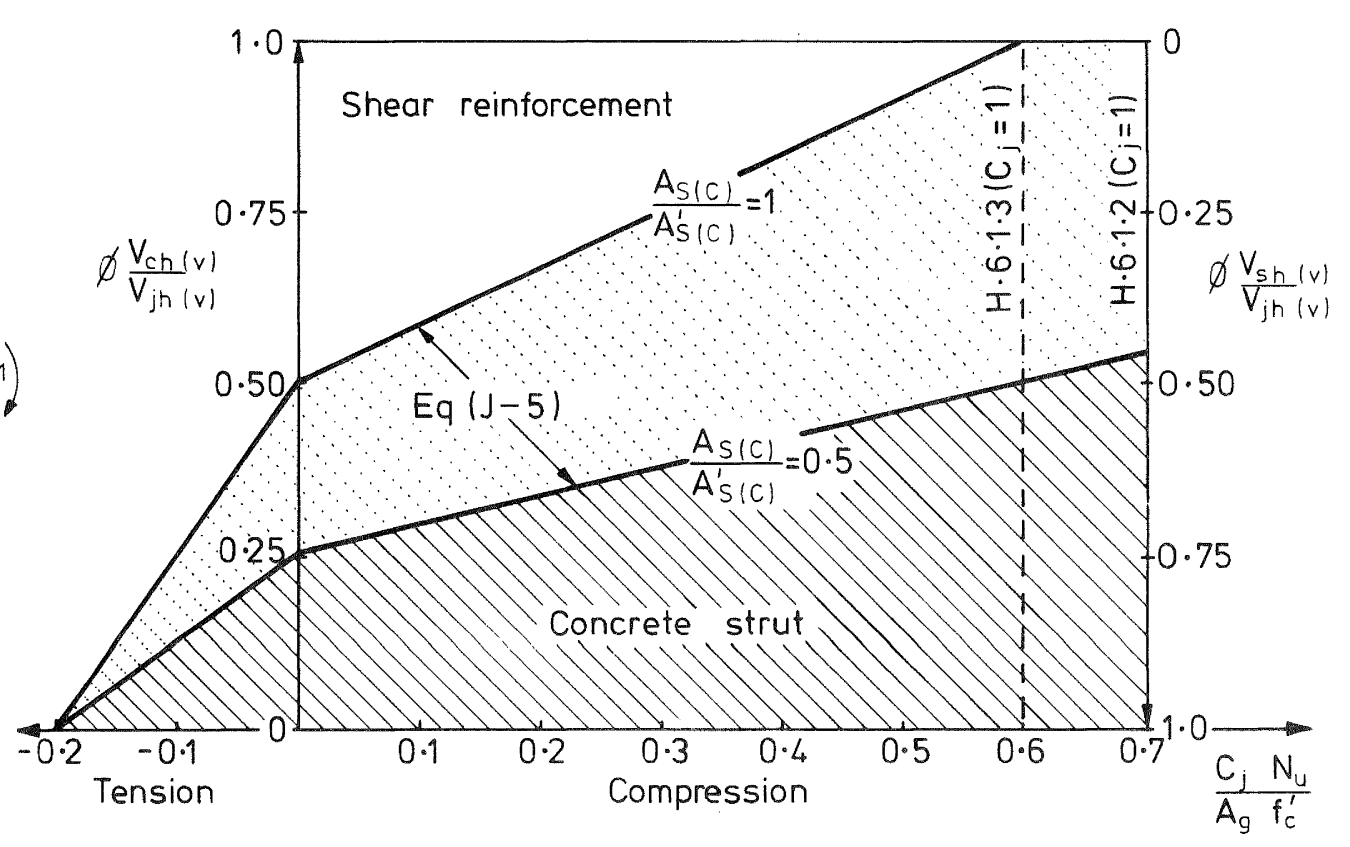

FIGURE CJ5: NOMINATED CONTRIBUTION OF DIAGONAL STRUT ACTION TO VERTICAL AND HORIZONTAL JOINT SHEAR RESISTANCE 
ADDENDUM: WORKED EXAMPLES

The following worked examples illustrate application of the provisons of this section to design of beam-column joints. The examples chosen are a conventional beamcolumn joint, designed to form plastic hinges in the beams adjacent to the joint, with and without column axial load, and an "elastic" joint with beam plastic hinges designed to form the required distance away from the column face.

Details of all concentrated forces in the members have been shown for illustration. Only the concentrated beam forces and column shear need be calculated during routine design. In derivation of the diagonal strut force, $D$, the assumption has been made in Examples 1 and 2 that there is a linear rate of change of stress in the flexural reinforcement between the maximum tension and compression values at opposite column faces. Experimental evidence (4) supports this assumption at the stage of cyclic loading illustrated in the example, before wide full-depth cracks have formed in the beams and there has been yield penetration along the flexural reinforcement into the joint. The bond forces from the flexural reinforcement within the assumed bounds of the principal diagonal compression strut have been taken as contributing to the principal diagonal strut force, D. In Example 3 the simplifying assumption has been made that the flexural steel compressive force only is anchored within the bounds of the diagonal strut and contributes to that force. In all cases it has been assumed that beam and column shear forces are transferred in the respective member compression zones only.

The procedure illustrated in Examples $I$ and 2 for the calculation of the mean effective area of the tie sets was as follows. Lines corresponding to the intersection of the plane of the corner-to-corner diagonal crack and the planes of each tie set were projected on to the plan view of the column. The sum of the components of area of the tie legs, $A_{l}$, crossing the crack in the direction of the joint shear force has been shown for each tie set. A mean effective area of all tie sets has then been calculated. A simpler but more conservative procedure would have been to neglect the legs of the rectangular tie not extending full depth in each set, and directly derive the mean effective area as $(4+\sqrt{2}) \mathrm{A}_{\ell}=5.4 \mathrm{Al}$. This procedure was followed in Example 3. 


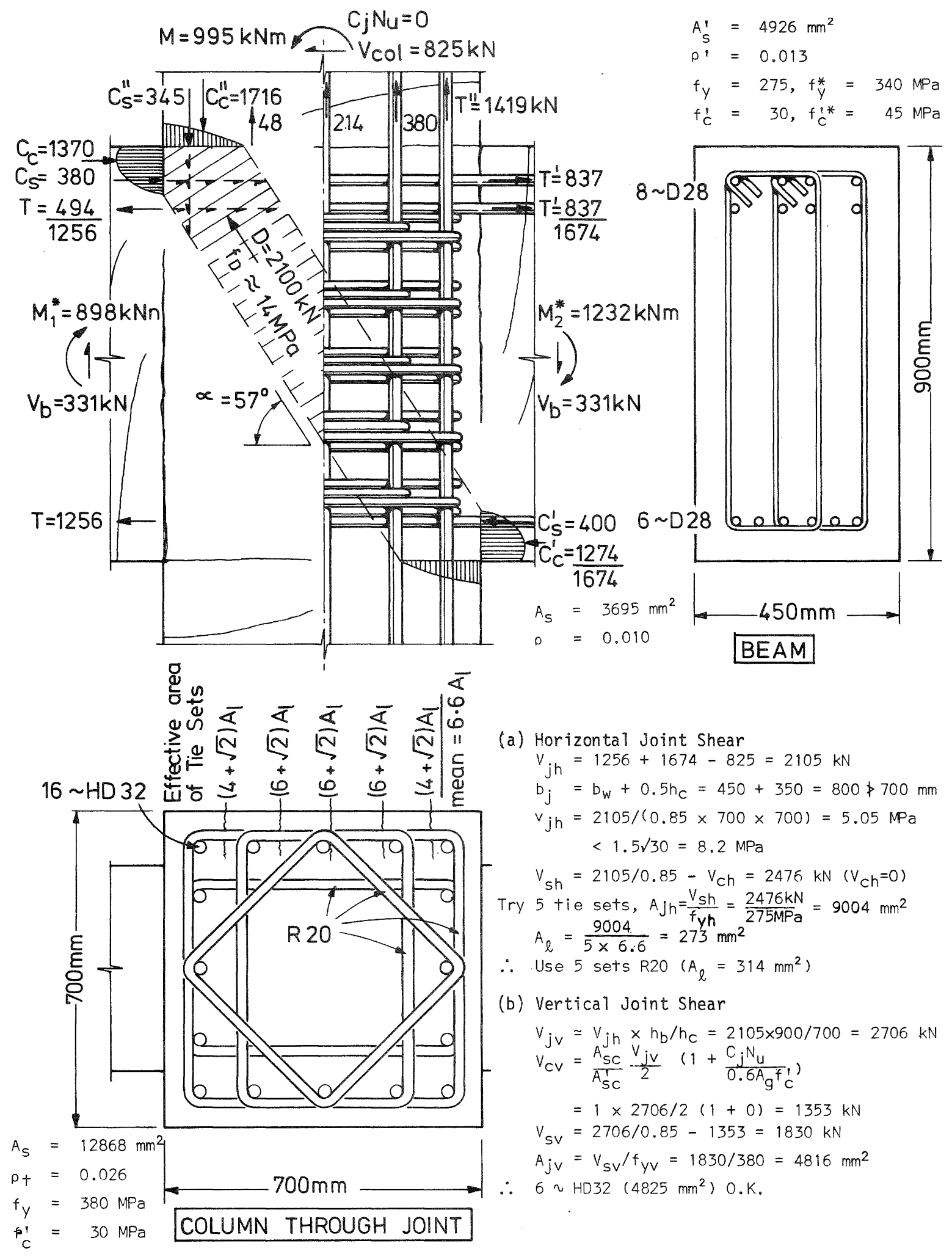




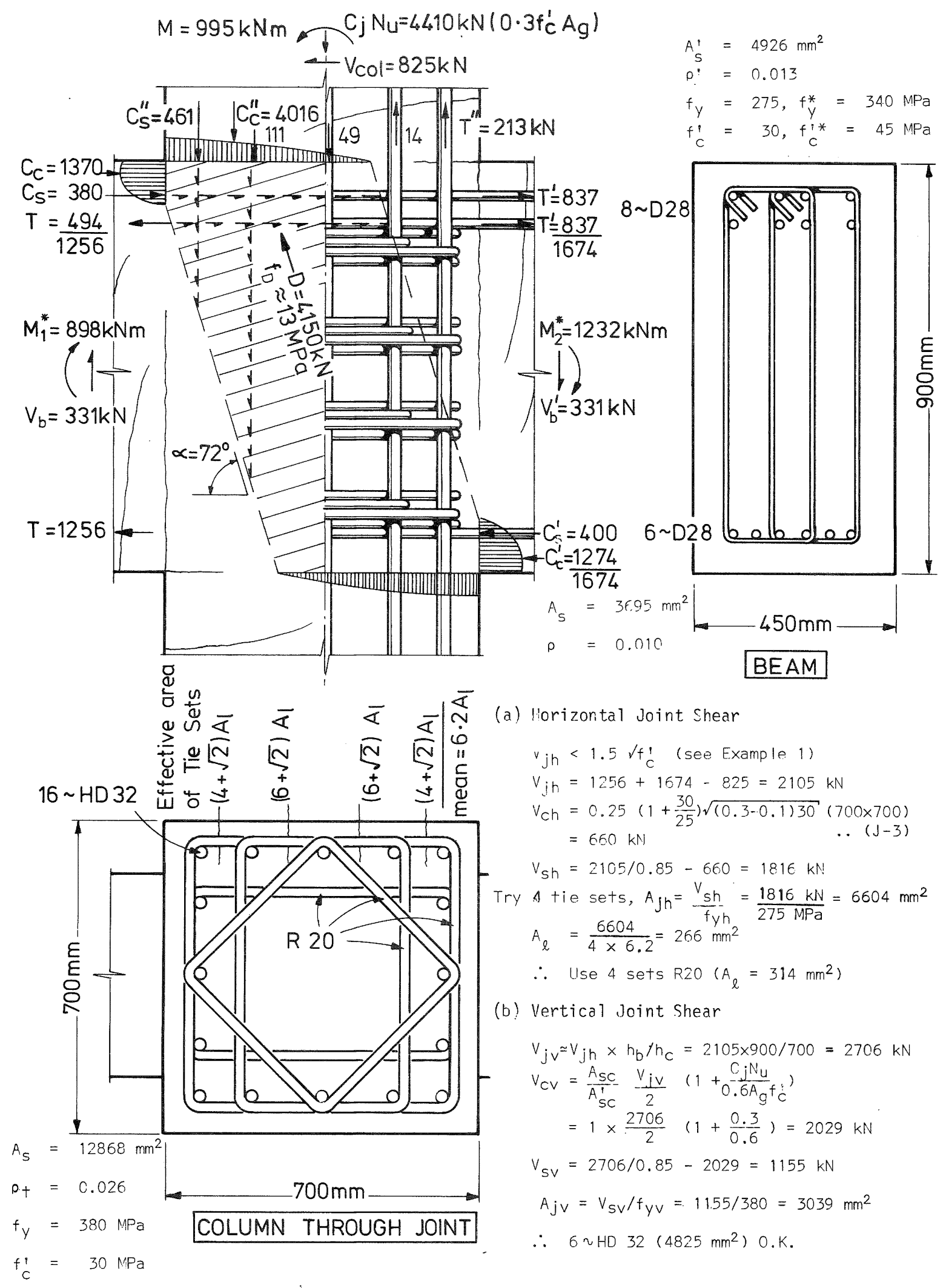

EXAMPLE 2: COLUMN WITH AXIAL LOAD 

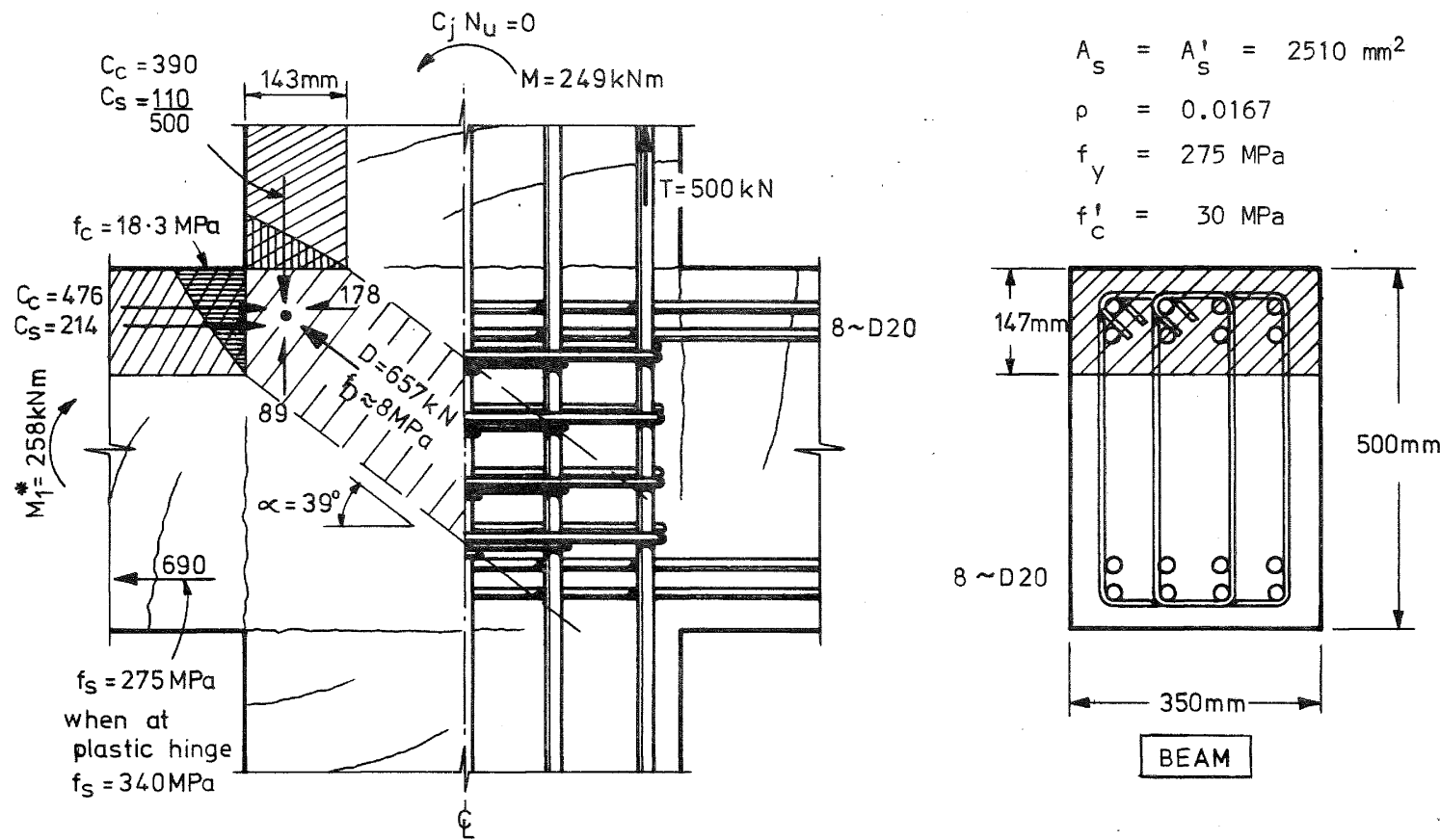

(a) Horizontal Joint Shear

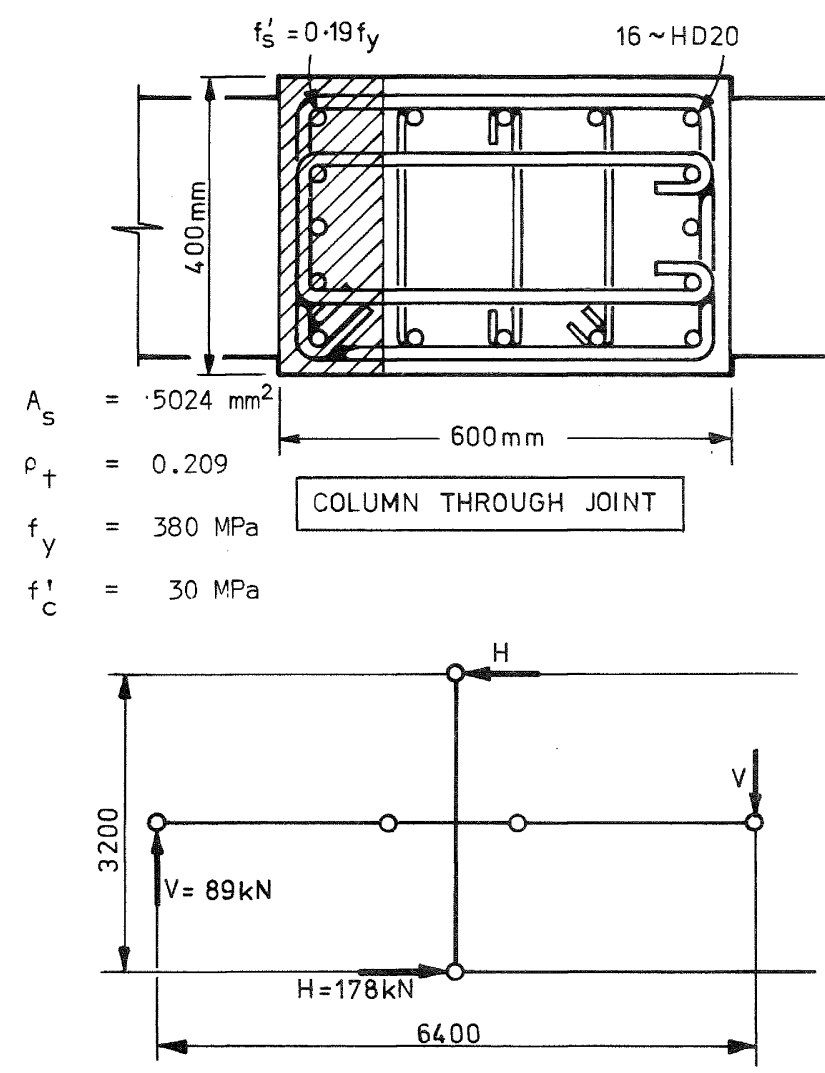

$v_{j h}=476+214+690-178=1202 \mathrm{kN}$

$v_{j h}=1202 /(0.85 \times 400 \times 600)=5.9 \mathrm{MPa}$ $<1.5 V_{f}^{\prime}=8.2 \mathrm{MPa}$

$V_{c h}=\frac{A_{s}}{A_{s}^{\prime}}-\frac{V_{j h}}{2}\left(1+\frac{C_{j} N^{N}}{0.6} A_{g} f_{c}^{\prime}\right)$

$=1 \times \frac{1202}{2}(1+0)=601 \mathrm{kN}$

$v_{s h}=1202 / 0.85-v^{601}=813 \mathrm{kN}$ Try 4 tie sets, $A_{j h}=\frac{s h}{f_{y h}}=\frac{813 \mathrm{kN}}{275 \mathrm{MPa}}=2956 \mathrm{~mm}^{2}$ $A_{2}=\frac{2956}{4 \times 4}=185 \mathrm{~mm}^{2}$

$\therefore$ Use 4 sets R16 $\left(A_{l}=201 \mathrm{~mm}^{2}\right)$

(b) Vertical Joint Shear

$v_{j V}=390+110+500-89=911 \mathrm{kN}\left(V_{j h} \times \frac{h_{b}}{h_{c}}=1002\right)$

$v_{c V}=\frac{A_{S C}}{A_{S C}^{\prime}} \frac{v_{j v}}{2}\left(1+\frac{C_{j} N_{u}}{0.6 A_{g} f_{C}^{\prime}}\right)$

$=1 \times \frac{911}{2}(1+0)=455 \mathrm{kN}$

$V_{S V}=911 / 0.85-455=617 \mathrm{kN}$

$A_{S V}=V_{s V} / f_{y v}=617 / 380=1623 \mathrm{~mm}^{2}$

$\therefore \quad$ Use $6 \sim$ HD $20\left(1884 \mathrm{~mm}^{2}\right)$

EXAMPLE 3: "ELASTIC" BEAM-COLUMN JOINT 